\section{OBESITY, INSULIN RESISTENCE AND METABOLIC SYNDROME RELATED COMPONENTS AMONG SPANISH CHILDREN}

E. García-García ${ }^{1}$, R. Galera², M.-Á. Vázquez², A. Bonillo ${ }^{2}$

${ }^{1}$ Pediatric Endocrinology, Virgen del Rocío Hospital, Sevilla, ${ }^{2}$ Pediatrics, Torrecárdenas Hospital, Almería, Spain

Purposes: To report the prevalence of obesity and overweight among 4-12 year old children living in the city of Almería (south of Spain). To examine the distribution of HOMA-IR (homeostasis model assessment of insulin resistance) and metabolic syndrome (MS) related components in these children.

Methods: A total of 610 subjects (51,0\% girls) attending primary school (aged 4 - 12 years) participated in a community-based cross-sectional survey. IOTF (International Obesity Task Force) criteria were used to identify obesity and overweight. Criteria for central obesity was waist circumference $>$ or $=90^{\text {th }}$ percentile, age and gender specific. Blood pressure, fasting glucose, insulin, triglyceride and HDL-cholesterol concentrations were mesured and HOMA-IR was calculated.

Results: $12.8 \%$ of this sample were obese and $29.0 \%$ overweight. HOMA-IR (mean \pm standard deviation) was $1.18 \pm 0.9$. Central obese children show higher insulin levels $(9.9 \pm 6.2$ vs $5.1 \pm 3.4$ $\mathrm{mcU} / \mathrm{ml}$; $<<0.001)$, HOMA-IR $(2.0 \pm 1.3$ vs $1.0 \pm 0.7$; $p<0.001)$, systolic blood pressure $(113 \pm 14 \mathrm{~mm} \mathrm{Hg}$ vs $105 \pm 12 ; p<0.001)$ and triglyceride levels (78 \pm 38 vs $63 \pm 13$ mg/dl; $p<0.001$ ), and lower HDLcholesterol levels $(57 \pm 12$ vs $64 \pm 13 \mathrm{mg} / \mathrm{dl}$; $p<$ 0.001 ) than non central obese children.

Conclusions: Obesity and overweight are major problems for Spanish children. Insulin resistence and metabolic syndrome related components are related to central obesity in primary school children.

\section{UK PARENTS' BELIEFS ABOUT INFANT GROWTH AND FEEDING IN RELATION TO OBESITY PREVENTION}

S. Redsell ${ }^{1}$, P. Atkinson ${ }^{2}$, D. Nathan ${ }^{3}$, A.N. Siriwardena ${ }^{4}$, J. Swift ${ }^{5}$, C. Glazebrook ${ }^{6}$

${ }^{1}$ School of Nursing, Midwifery and Physiotherapy, University of Nottingham, ${ }^{2}$ Nottingham City PCT, ${ }^{3}$ Nottingham University Hospitals NHS Trust, Nottingham, ${ }^{4}$ School of Health and Social Care, University of Lincoln, Lincoln, ${ }^{5}$ School of Biosciences, ${ }^{6}$ School of Community Health

Sciences, University of Nottingham, Nottingham, UK

Objectives: A number of modifiable risk factors are associated with the development of childhood obesity. These are lower breast feeding duration, early weaning onto solid foods, parental response to infant temperament and parental control over food intake. This study explored parents' beliefs concerning their infant's size and growth and their receptiveness to early intervention aimed at reducing the risk of childhood obesity.

Method: Six focus groups were undertaken, in a range of different demographic areas, with parents of infants less than one year old. The focus groups were audio-recorded, transcribed verbatim and subjected to thematic analysis using an interpretative, inductive approach.

Results: 38 parents ( $n=36$ female, $n=2$ male), age range 19-45 years (mean 30.1 years, SD 6.28) participated in the focus groups. Half the sample were overweight $(n=12)$ or obese $(n=8)$. Five main themes were identified. These were a) rationalisation for infant's larger size, b) parents' understanding of breastfed infants' growth and age-related behaviour; c) parents' understanding of infant growth, developmental norms and feeding practices, d) belief that nothing can be done about overweight/obese infants and e) intentions and behaviour in relation to a healthy diet. Conclusions: Some risk factors for childhood obesity are potentially modifiable. Parents are receptive to prevention prior to weaning and need better support with best practice in infant feeding. This should focus on helping them understand the physiology of breast feeding, the rationale around weaning at 6 months and how to recognise that hunger is only one explanation for infant distress and behaviour change. 